\title{
PREMISSAS DE INCLUSÃO DIGITAL NA FORMAÇÃO INICIAL DE EDUCADORES: UM ESTUDO MULTICASO REALIZADO NO BRASIL E EM PORTUGAL
}

\author{
Karina Marcon ${ }^{1}$ \\ Marie Jane Soares Carvalho ${ }^{2}$
}

\section{INTRODUÇÃO}

Esse artigo tem por objetivo apresentar os resultados de uma pesquisa doutoral, que buscou analisar a compreensão e a prática da inclusão digital na formação inicial de educadores na modalidade a distância das Universidades Abertas do Brasil e de Portugal. Para concretização deste estudo, foram realizadas pesquisas em teses e dissertações para a criação de um estado da arte sobre o conceito de inclusão digital e uma pesquisa de campo nos cursos de Licenciatura em Educação (Universidade Aberta de Portugal) e Pedagogia a Distância (Universidade do Estado de Santa Catarina). Uma das categorias de análise da pesquisa teve como intuito compreender o conceito de inclusão digital adotado nos projetos dos cursos, análise apresentada nesse texto.

\section{METODOLOGIA}

Esta pesquisa foi concretizada por meio de um estudo multicaso, entendido por Triviños como um método no qual, "sem necessidade de perseguir objetivos de natureza comparativa, o pesquisador pode ter a possibilidade de estudar dois ou mais sujeitos, organizações etc." (1987, p. 136). Foi nesse sentido que orientamos nossa metodologia de pesquisa, isso é, não com finalidade comparativa, mas com natureza exploratória de conhecer as realidades e, a partir dessas, construir análises, relações e inferências.

\footnotetext{
${ }^{1}$ Doutora em Educação pela Universidade Federal do Rio Grande do Sul (UFRGS). Realizou estágio de Doutorado na Universidade Aberta de Lisboa/Portugal. Professora do Centro de Educação a Distância (CEAD) da Universidade do Estado de Santa Catarina (UDESC). E-mail: karina.marcon@udesc.br

${ }^{2}$ Doutora em Educação pela Universidade Federal do Rio Grande do Sul (UFRGS). Realizou estágio de Doutorado na University of Toronto e Pós-Doutorado na UNED/ Madrid. Professora Titular no Departamento de Ensino e Currículo da Faculdade de Educação da UFRGS. Docente no Programa de Pós-Graduação em Informática na Educação (PPGIE). E-mail: marie.jane@ufrgs.br
} 
Para concretização do estado da arte sobre o conceito de inclusão digital partimos de estudos prévios realizados na área e fizemos um levantamento bibliográfico em teses de doutorado e dissertações de mestrado defendidas entre 2011 e 2014 no Brasil e em Portugal. No Brasil elegemos a Biblioteca Brasileira de Teses e Dissertações (BDTD) e encontramos 12 teses e dez dissertações. Em Portugal utilizamos o Repositório Científico de Acesso Aberto de Portugal (RCAAP), e a pesquisa se concretizou com duas teses e 12 dissertações.

Já para desvelar como é concebido o conceito de inclusão digital em ambos os cursos, foi feita uma pesquisa documental no Projeto Pedagógico do Curso (PPC) da Pedagogia a Distância do Centro de Educação a Distância da Universidade do Estado de Santa Catarina, bem como no Relatório de Apresentação do Curso de Licenciatura em Educação da Universidade Aberta. Nossas perguntas, na leitura desses documentos, eram as seguintes: Existe um conceito de inclusão digital? De que forma é apresentado? Como considera a utilização das tecnologias digitais de rede na educação?

\section{RESULTADOS E DISCUSSÃO}

Ao refletir sobre as contribuições trazidas pelos pesquisadores que visitamos no estado da arte brasileiro e também em estudos anteriores, elencamos a seguir algumas características que julgamos fundamentais ao pensarmos o conceito de inclusão digital:

Democratizar o acesso às tecnologias digitais e garantir a equidade (MEDEIROS, 2013; DUSYK, 2013; CASARIN, 2014);

> Permitir, na apropriação tecnológica, que as pessoas atuem como provedores ativos dos conteúdos que circulam na rede (TAKAHASHI, 2000; BONILLA, 2004; TEIXEIRA, 2010a; ODANAI, 2013);

> Vivenciar uma cultura de redes (PRETTO, 2006; TEIXEIRA, 2010a);

> Promover a utilização das tecnologias a favor dos interesses e necessidades individuais e comunitários, com responsabilidade e 
senso de cidadania (TAKAHASHI, 2000; TEIXEIRA, 2010a; RODRIGUEZ, 2011; RIBEIRO, 2012; SANTOS, 2012);

Valorizar a diversidade (TEIXEIRA, 2010a; PEDROSA, 2011);

> Desenvolver habilidades e capacidades para a era digital (ODAINAI, 2013);

> Romper o ciclo de consumo e dependência tecnocultural (TEIXEIRA, 2010a);

> Buscar a fluência digital, com processos que aprimorem a ação e a autonomia dos sujeitos e o exercício da liberdade e da cidadania na rede (TEIXEIRA, 2010a; PEDROSA, 2011; ALENCAR, 2013; BOTELHO-FRANCISCO, 2014);

> Compreender inclusão digital como um conceito multidimensional, que envolve dimensões digital, informacional e social (PEREIRA, 2014; ARAÚJO, 2013).

Já ao findar o mapeamento teórico sobre inclusão digital em Portugal, destacamos principalmente a compreensão desses trabalhos pelo conceito de literacia digital, que expressa a necessidade de que se faça um uso eficiente das Tecnologias Digitais de Rede (TDR) contemporâneas, além de reconhecer a transformação gerada pela cultura digital, o potencial das tecnologias para a vida humana e para a educação, a necessidade de usabilidade técnica e o desenvolvimento de competências, bem como a urgência de assumir-se como um ser produtor de conhecimento, de conteúdos e de cultura.

Diante da diversidade de perspectivas teóricas e da complexidade entorno da temática central deste estudo, propomos um conceito de inclusão digital que subsidia nossas análises e inferências. Partimos dos resultados encontrados no estado da arte brasileiro e do mapeamento teórico do contexto português, associando-os a estudos, pesquisas e experiências anteriores.

Compreendemos inclusão digital como um processo que fomenta apropriações tecnológicas nas quais os sujeitos são compreendidos como produtores ativos de conhecimento e de cultura, em uma dinâmica reticular que privilegia a vivência de características nucleares na sociedade contemporânea, como a interação, a autoria e a colaboração. Inclusão digital pressupõe o empoderamento das pessoas por meio das tecnologias, a garantia à equidade social 
e à valorização da diversidade, suprindo necessidades individuais e coletivas, visando à transformação das próprias condições de existência e o exercício da cidadania na rede.

Assim, entendemos que o conceito de inclusão digital perpassa por três eixos, descritos a seguir.

1) Apropriação/Fluência/Empoderamento Tecnológico.

2) Produção/Autoria individual/coletiva de conhecimento e de cultura.

3) Exercício da cidadania na rede.

O eixo 1 - Apropriação/Fluência/Empoderamento Tecnológico - diz respeito ao acesso, à apropriação, ao domínio e à fluência tecnológica, elementos necessários para reconhecer e transitar pela linguagem hipermidiática, condutora da cultura digital. É nesse eixo que dialogamos com os diferentes níveis de apropriação tecnológica e letramento digital, reconhecendo a necessidade de se assegurar a equidade de acesso, bem como oportunizar o empoderamento dos sujeitos por meio das tecnologias digitais de rede, reconhecendo seu potencial comunicacional, educativo e político.

O eixo 2 - Produção/Autoria individual/coletiva de conhecimento e cultura - compreende os sujeitos como autores e produtores ativos de conhecimento e de cultura. As tecnologias digitais de rede potencializam a vivência de processos comunicacionais interativos, autorais e colaborativos. Com a abertura dos polos de emissão, a cibercultura autoriza o sujeito a se expressar, interagir e participar. Supera-se a comunicação unidirecional e os limites temporais e espaciais, privilegiase a interação todos-todos. É nesse eixo que correlacionamos a inclusão digital com a apropriação crítica e criativa das tecnologias digitais de rede, na qual os sujeitos, além de consumidores, são autorizados a criar, produzir e compartilhar informações, conhecimentos e cultura.

O eixo 3 - Exercício da cidadania na rede - refere-se à garantia de participação política dos sujeitos no ciberespaço e à valorização da diversidade social. Reconhecemos que a apropriação tecnológica pode acontecer de acordo com a realidade e interesses de cada sujeito, isso é, cada um apropria-se das tecnologias de acordo com as suas necessidades individuais, coletivas ou comunitárias. Nesse eixo, fazemos uma interlocução com propostas que objetivam o 
reconhecimento das tecnologias digitais de rede como propulsoras de transformação das próprias condições de existência e do exercício da cidadania na rede.

Já com relação ao objetivo de desvelar como é concebido o conceito de inclusão digital nos cursos, no Relatório de Apresentação do Curso de Licenciatura em Educação identificamos objetivos concernentes à formação dos estudantes em uma perspectiva de apropriação das tecnologias digitais para o exercício de sua prática profissional, questão observada quando o documento relata que espera-se que o profissional em formação desenvolva diferente capacidades, entre elas "utilizar eficientemente as ferramentas tecnológicas em diversos contextos educativos" (UAb, Relatório Licenciatura Educação, 2006, p. 11).

Assim, após analisar o Relatório de Apresentação do Curso de Licenciatura em Educação, entendemos que em sua essência a concepção do curso considera fundamental a aprendizagem no contexto das tecnologias educacionais, principalmente como objetivo de tornar o licenciado capaz de utilizar esses recursos nos diferentes espaços educativos em que possa atuar enquanto profissional.

Outros objetivos correlacionados com a perspectiva da inclusão digital também foram encontrados no Relatório de Apresentação do Curso de Licenciatura em Educação, e destacamos fundamentalmente a ênfase do curso em formar profissionais que privilegiem aspectos relativos à inovação educativa por meio da aplicação de tecnologias digitais em contextos educativos diversos. Por fim, na análise do relatório encontramos referência a perspectivas formativas que entendem ser fundamental perpassar pela aprendizagem no contexto das tecnologias educacionais, principalmente como o objetivo de tornar o licenciado capaz de fazer uso desses recursos em suas atividades laborais.

Com relação ao curso de Licenciatura em Pedagogia do Cead/Udesc, encontramos no Projeto Pedagógico uma formação estruturada com ênfase nas tecnologias de informação e comunicação. Observamos essa perspectiva em diversos momentos no PPC, que fundamentalmente recomenda a busca por "proporcionar a formação inicial para o exercício da docência, prioritariamente na Educação Infantil e Anos Iniciais do Ensino Fundamental, com ênfase no uso das tecnologias da informação e da comunicação [...]" (UDESC, PPC Pedagogia, 2009, p. 04). As tecnologias são consideradas centrais na formação desses estudantes.

Após percorrer o Projeto Pedagógico do Curso de Pedagogia do Cead/Udesc, compreendemos que, em sua essência, a concepção do curso 
considera fundamental perpassar pela aprendizagem no contexto das tecnologias de informação e comunicação, principalmente com o objetivo de tornar o licenciado capaz de utilizar os recursos nos diferentes espaços educativos em que poderá atuar como profissional. Apesar de não encontrarmos um conceito de inclusão digital explícito, entendemos que é um projeto que avança em questões relacionadas à inclusão digital e à educação a distância, principalmente por enfocar essa relação com as TICs de forma evidente em várias diretrizes e objetivos do curso. Além disso, julgamos que as disciplinas que fazem relação com EAD podem promover uma formação sólida e significativa na área das TICs, desde que suas concepções pedagógicas efetivamente evidenciem essa apropriação.

\section{CONCLUSÃO}

Após analisar os projetos dos cursos compreendemos que, em sua essência, ambos consideram fundamental perpassar pela aprendizagem no contexto das tecnologias de informação e comunicação, principalmente com o objetivo de tornar o licenciado capaz de utilizar os recursos nos diferentes espaços educativos em que poderá atuar como profissional. Explicitamente não encontramos conceitos de inclusão digital nos projetos dos cursos, mas ambos enfatizam o uso das tecnologias de informação e comunicação, bem como o desenvolvimento de competências digitais na formação dos estudantes.

Uma outra perspectiva encontrada em ambos os Projetos é a formação dos estudantes para que sejam capazes de conceber, desenvolver e gerir programas de formação na modalidade a distância. No curso de Licenciatura em Educação isso desenvolve-se a partir dos pressupostos do Maior Fundamentos em Educação (ciclo básico para todos os estudantes), mas aprofunda-se aos estudantes que optam pelo Minor em Pedagogia Social e da Formação. Já no curso de Pedagogia do Cead/Udesc, essa formação incide por meio de seis disciplinas que são direcionadas para o estudo específico da metodologia dos processos educativos na modalidade a distância: Fundamentos da Educação a Distância, Didática da Educação a Distância, Metodologia da Educação a Distância I, Metodologia da Educação a Distância II, Produção de Material Didático para a Educação a Distância e Gestão da Educação a Distância. 
O PPC do curso de Pedagogia destaca também o desenvolvimento de habilidades e competências relacionadas ao uso das TICs, que envolvem desde o estabelecimento de relações entre a linguagem multimídia e os processos educativos, até a proposição de ações criativas de ensino que visam a superação da exclusão social e digital.

Por fim, os dois documentos não possuem, explicitamente, um conceito de inclusão digital, mas em suas essências compreendem que durante a formação os estudantes precisam desenvolver competências digitais e perpassar seus processos de aprendizagem no âmbito das tecnologias aplicadas a contextos educativos. Sobre essa categoria, entendemos que são as diretrizes dos projetos dos cursos que conduzem as práticas metodológicas e pedagógicas que serão exercidas nos mesmos, por isso a importância da participação democrática na elaboração desses documentos.

\section{REFERÊNCIAS}

ALENCAR, Maria da Glória Serra Pinto de. A política brasileira de inclusão digital no capitalismo contemporâneo: o elo perdido do Programa Casa Brasil. Tese (Doutorado em Políticas Públicas). Centro de Ciências Sociais, Universidade Federal do Maranhão. São Luis, 2013. Disponível em: $<$ http://www.tedebc.ufma.br//tde_busca/arquivo.php?codArquivo =832>. Acesso em: 02 out. 2014.

ARAÚJO, Marcelo Henrique de. Análise de Fatores que influenciam o uso de serviços de Governo Eletrônico no Brasil. Dissertação (Mestrado em Administração). Faculdade de Economia, Administração e Ciências Contábeis da Universidade de São Paulo. São Paulo, 2013. Disponível em: <http://www.teses.usp.br/teses/disponiveis/12/12139/tde-05122013-185015/ptbr.php>. Acesso em: 01 out. 2014.

BONILLA, Maria Helena. Educação e Inclusão Digital. GEC: Grupo de Pesquisa em Educação, Comunicação e Tecnologias, 2004. Disponível em: <http://www.twiki.ufba.br/twiki/bin/view/GEC/MariaHelenaBonillas. Acesso em 26 out. 2012.

BOTELHO-FRANCISCO, Rodrigo Eduardo. Interatividade e literacias emergentes em contextos de inclusão digital: um estudo netnográfico no programa AcessaSP. Tese (Doutorado). Escola de Comunicação e Artes. Universidade de São Paulo. São Paulo, $2014 . \quad$ Disponível em: $<$ http://www.teses.usp.br/teses/disponiveis/27/27154/tde-20052014-152952/ptbr.php>. Acesso em: 05 out. 2014. 
CASARIN, Melânia de Melo. O Programa Um Computador por Aluno (PROUCA) e a Inclusão de alunos com deficiência. Tese (Doutorado em Educação). Faculdade de Educação, Universidade Federal do Rio Grande do Sul. Porto Alegre, 2014. Disponível em: <http://www.lume.ufrgs.br/handle/10183/98598>. Acesso em: 05 out. 2014.

DUSYK, Claudio Luciano. Teclado Virtual Silábico-Alfabético: Tecnologia Assistiva para Pessoas com Deficiência Física. Dissertação (Mestrado em Educação). Faculdade de Educação, Universidade Federal do Rio Grande do Sul. Porto Alegre, 2013. Disponível em: <http://www.lume.ufrgs.br/handle/10183/79640>. Acesso em: 30 set. 2014.

MEDEIROS, Ana Claudia Jacinto Peixoto de. Análise das políticas de inclusão digital da rede pública municipal de ensino de Uberlândia no período 19992012. Dissertação (Mestrado em Educação). Universidade Federal de Uberlândia, 2013. Disponível em: <http://www.bdtd.ufu.br//tde_busca/arquivo.php?codArquivo=4967>. Acesso em: 28 set. 2014.

ODAINAI, Alexandre Alves Sinfronio. A cultura participativa na educação: superando a perspectiva instrumental no uso dos mecanismos de comunicação digital nos sistemas básico e médio de ensino. 2013. Dissertação (Mestrado) Programa de Estudos Pós-Graduados em Comunicação e Semiótica / PEPGCOS, Pontifícia Universidade Católica de São Paulo (PUC-SP), São Paulo: 2013. Disponível em: <http://www.sapientia.pucsp.br//tde_buscal arquivo.php?codArquivo=15923 >. Acesso em: 26 set. 2014.

PEDROSA, Neide Borges. Comunidade de formação e prática pedagógica indígena: inclusão digital e identidade cultural. 2011. Tese (Doutorado em Educação) - Programa de Pós-Graduação em Educação: Currículo, Pontifícia Universidade Católica de São Paulo, São Paulo: 2011. Disponível em: <http://www.sapientia.pucsp.br// tde_busca/arquivo.php?codArquivo=14270>. Acesso em: 12 set. 2012.

PEREIRA, Luís Miguel Gonçalves. Conceções de literacia digital nas políticas públicas: estudo a partir do Plano Tecnologico de Educação. 2012. Tese (Doutoramento em Ciências da Comunicação). Instituto de Ciências Sociais, Universidade do Minho. Minho: 2012. Disponível em: <http://hdl.handle.net/1822/19825>. Acesso em: 12 set. 2012.

PRETTO, Nelson de Luca. Políticas públicas educacionais no mundo contemporâneo. Liinc em Revista, v. 2, p. 10-27, 2006. Disponível em: <https://blog.ufba.br/nlpretto/? page_id=388>. Acesso em: 26 out. 2012.

RIBEIRO, Raimundo Nonato Costa. O uso de tecnologias assistivas no ensino de pessoas com deficiência visual no curso técnico de Informática na Escola Professor Raimundo Franco Teixeira/ SENAI/ São Luís do Maranhão. 2012. Dissertação (Mestrado em Docência e Gestão da Educação). Faculdade de Ciências Humanas e Sociais, Universidade Fernando Pessoa. Disponível em: $<$ http://bdigital.ufp.pt/bitstream/10284/3327/1/DM_23662.pdf>. Acesso em: 10 set. 2012. 
RODRIGUEZ, Carla Lopes. A utilização de recursos audiovisuais em comunidades virtuais de aprendizagem: potencialidades e limites para comunicação e construção de conhecimentos em rede. 2011. Tese (Doutorado em Artes) - Programa de Pós-Graduação em Artes, Universidade Estadual de Campinas, $\quad$ Campinas, 2011.2 Disponível $<$ http://www.bibliotecadigital.unicamp.br/document/?code=000805896\&fd=y>. Acesso em: 10 set. 2012.

SANTOS, Pricila Kohls dos. Inclusão Digital de Professores: Uma proposta de construção de trajetórias personalizáveis em cursos na modalidade a distância. Dissertação (Mestrado em Educação). Programa de Pós-Graduação em Educação, Pontifícia Universidade Católica do Rio Grande do Sul. Porto Alegre: 2012. Disponível em: <http://tede.pucrs.br/tde_busca/arquivo.php?codArquivo=4114>. Acesso em: 16. set. 2012.

TAKAHASHI, Tadao. Sociedade da informação no Brasil: livro verde. Brasília: Ministério da Ciência e Tecnologia, 2000. Disponível em: <http://www.mct.gov.br/index.php/content /view/18878.html>. Acesso em: 02 jul. 2012.

TEIXEIRA, Adriano Canabarro. Inclusão digital: Novas perspectivas para a informática educativa. 1 ed. ljuí/RS: Edutora Unijuí, 2010a.

TRIVIÑOS, Augusto Nibaldo Silva. Introdução à pesquisa em ciências sociais: a pesquisa qualitativa em educação. São Paulo: Atlas, 1987.

UAb, Universidade Aberta. Relatório de Apresentação da Licenciatura em Educação. Departamento de Ciências da Educação. 1ำ Ciclo de Estudos. Coordenadora: Dr. Godoberta Andrade. Vice-coordenadora: Dr. Lúcia Amante. Lisboa: 2006.

UDESC, Universidade do Estado de Santa Catarina. Projeto Pedagógico do Curso de Pedagogia a Distância. 2009. Disponível em: <http://www.cead.udesc.br/?id=363>. Acesso em 09 dez 2014.

\section{Fonte Financiadora:}

Durante o Curso de Doutorado fui bolsista $\mathrm{CNPq}$, e para a concretização da pesquisa em Portugal realizei um estágio sanduíche na Universidade Aberta, em Lisboa/Portugal, sendo bolsista CAPES/PDSE. 